\title{
Acute respiratory distress syndrome
}

\author{
Susannah K Leaver, Timothy W Evans
}

Department of Critical Care, Imperial College School of Medicine, Royal Brompton Hospital, London SW3 6NP Correspondence to: T W Evans t.evans@rbht.nhs.uk

BMJ 2007;335:389-94 doi:10.1136/bmj.39293.624699.AD

\section{Why do I need to know about acute respiratory distress syndrome?}

Acute respiratory distress syndrome is the extreme manifestation of acute lung injury. Both these conditions complicate many medical and surgical conditions, not all of which affect the lung directly and are therefore encountered by clinicians working outside the critical care setting with varying frequency. Early recognition is important in determining outcome, as prognosis is usually dependent partly on the nature and prompt management of the precipitating condition.

\section{How are these conditions defined?}

Acute lung injury and acute respiratory distress syndrome are defined by refractory hypoxaemia (using the $\mathrm{PaO}_{2}$ to $\mathrm{FiO}_{2}$ ratio) in association with bilateral lung infiltrates on chest radiography, in the absence of left atrial hypertension (thereby excluding hydrostatic pulmonary oedema as a cause) but in the presence of a clinical condition known to precipitate the syndrome (box 1).

Although the definition criteria outlined in box 1 , developed in 1992, ${ }^{1}$ have facilitated the enrolment of patients with different underlying pathologies into large scale clinical trials, they are inadequate for several reasons. Firstly, they do not take into account the relevance of the precipitating condition to prognosis. Secondly, the most appropriate system of interpretation of chest radiographs is not defined. Thirdly, they fail to standardise the strategy of mechanical ventilatory support to be used when hypoxaemia is quantified. Consequently a further consensus conference was arranged in 2000, but no agreement concerning revised clinical definitions or criteria emerged. Indeed, the conference believed that the breadth and level of specificity of the existing definitions had enabled the easy recruitment of a large number of patients for inclusion in clinical trials of putative therapeutic interventions (personal communication).

As all patients with acute respiratory distress syndrome fulfil the defining criteria for acute lung injury, we will use the latter term to refer to both conditions throughout this review, except where evidence cited is applicable only to patients with acute respiratory distress syndrome.

\section{How often is it encountered?}

The 1992 definition (box 1) for acute lung injury enabled the first estimations of incidence to be made, which range between 4.8 and 34 per 100000 population a year, with substantial international variability. ${ }^{23}$ However, a recent prospective study in a single county in the United States, including over 1000 patients and performed over 14 months found the incidence of acute lung injury to be higher (78.9 per 100000 population), suggesting that some 190600 cases occur in the US each year. ${ }^{4}$

The incidence of acute respiratory distress syndrome is influenced by the underlying clinical condition (table 1) being highest in patients with sepsis, severe sepsis, and septic shock and lower in patients with trauma. ${ }^{3}$ Other factors affecting incidence include advanced age and alcohol consumption. ${ }^{7}$ The extent to which the precipitating condition affects the lung directly or indirectly seems to influence lung compliance and recruitment (that is, opening up collapsed alveoli), appearances on computed tomography, and possibly clinical outcome. ${ }^{89}$

\section{How is acute lung injury recognised?}

Patients present either with acute lung injury or full blown acute respiratory distress syndrome, which may have prognostic significance. Some $55 \%$ of patients with acute lung injury seem to develop acute respiratory distress syndrome within three days of admission to an intensive care unit. ${ }^{10}$ In practice, most patients present clinically with dyspnoea, which may be masked by symptoms attributable to the precipitating condition. Clinical signs are those of pulmonary oedema of varying severity. The differential diagnosis is therefore relatively limited (box 2).

\section{What is the pathophysiology of acute lung injury?}

Genetic susceptibility to the development of acute lung injury has been suggested through the demonstration in relevant populations of genetic polymorphisms in the expression of genes encoding specific pathophysiological pathways. Acute respiratory distress syndrome

\section{SOURCES AND SELECTION CRITERIA}

We searched various sources to identify relevant evidence concerning the definition, epidemiology, and management and prognosis of patients with acute lung injury and acute respiratory distress syndrome. These included Medline, the Cochrane Library, conference proceedings, websites for specific clinical trials, and ClinicalTrials.gov (a website sponsored by the US National Institutes of Health that provided information about federally and privately supported clinical research in human volunteers) 
Box 1 Definition criteria for acute lung injury and acute respiratory distress syndrome ${ }^{1}$

In the appropriate clinical setting with one or more recognised risk factors, three criteria are required:

- Radiological-New, bilateral, diffuse, patchy, or homogeneous pulmonary infiltrates on chest radiograph consistent with pulmonary oedema

- Exclusion-No clinical evidence that heart failure, fluid overload, or chronic lung disease are responsible for the infiltrates; or pulmonary artery occlusion pressure of $18 \mathrm{~mm} \mathrm{Hg}$

- Oxygenation- $\mathrm{PaO}_{2}: \mathrm{FiO}_{2}$ ratio of $<40 \mathrm{kPa}$ (acute lung injury); $\mathrm{PaO}_{2}: \mathrm{FiO}_{2}$ ratio of $<26 \mathrm{kPa}$ (acute respiratory distress syndrome)

is characterised histopathologically by evidence of alveolar inflammation and injury leading to increased pulmonary capillary permeability. The syndrome is known to evolve through exudative, inflammatory, and fibroproliferative (or reparative) phases, usually over a total period of two to three weeks. The clinical consequences are impaired gas exchange with refractory hypoxaemia resulting from ventilation perfusion mismatch, physiological shunting, atelectasis of lung units, and reduced compliance, one of the hallmarks of acute respiratory distress syndrome. Rare complications are progressive pulmonary fibrosis and pulmonary hypertension, both of which have adverse prognostic significance.

\section{What investigations should be performed?}

Investigations aim to diagnose acute lung injury and acute respiratory distress syndrome, define the extent of lung injury, and help to elucidate the precipitating condition (see table 2). Use of computed tomography of the thorax is increasing as it is more sensitive than plain chest radiography in identifying pulmonary causes of acute respiratory distress syndrome and detecting complications. Computed tomography has also shown that acute respiratory distress syndrome does not affect the lung parenchyma homogeneously (figs 1 and 2).

\begin{tabular}{lcc}
\hline $\begin{array}{l}\text { Table } 1 \mid \text { Acute respiratory distress syndrome: common precipitating conditions with effect on } \\
\text { incidence and outcome } \star^{356}\end{array}$ & $\begin{array}{l}\text { Incidence of acute respiratory } \\
\text { distress syndrome (\%) }\end{array}$ & Mortality (\%) \\
Condition & 29 & 32 \\
\hline Sepsis syndrome & 38 & 36 \\
\hline Pneumonia & 15 & 29 \\
\hline Extra pulmonary source & 37 & 55 \\
\hline Septic shock & 48 & 56 \\
\hline Pulmonary source & 25 & 54 \\
\hline Extra pulmonary source & $12-18$ & 10 \\
\hline Trauma† & 29 & 57 \\
\hline Blood transfusion ( 8 units within 24 hours) & $22-38$ & 52 \\
\hline Gastrointestinal aspiration & & \\
\hline
\end{tabular}

* Similar data are not available for acute lung injury.

†Defined as multiple fractures with or without pulmonary contusion.

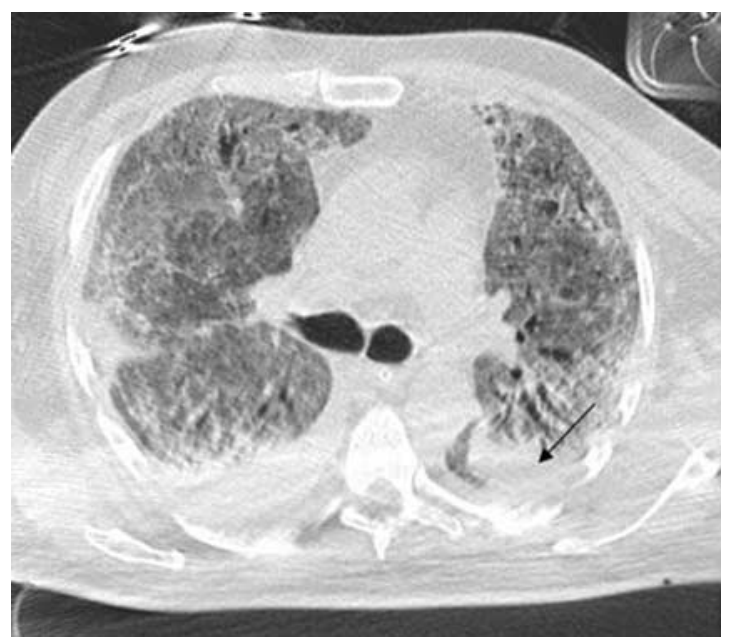

Fig 1 | Lung computed tomogram in a patient meeting the defining criteria for acute respiratory distress syndrome. The scan shows that acute respiratory distress syndrome does not affect the lung parenchyma homogeneously, with areas of dense opacification in dependent lung regions (arrow)

\section{How should these patients be managed?}

Treatment of patients with acute lung injury is essentially supportive, coupled with aggressive management of the precipitating condition. Complications, which include the exacerbation of lung injury, multiple organ system failure, nosocomial pneumonia, deep vein thrombosis, and gastrointestinal bleeding must be minimised. Admission to an intensive care unit with experience in dealing with such cases is mandatory and may improve outcome. ${ }^{4}$

\section{General supportive measures \\ Nutrition}

The early provision of enteral nutrition (given in the semirecumbent position to reduce the risk of nosocomial pneumonia) is desirable in all critically ill patients. Although evidence is limited regarding the optimal composition, data show that there may be advantages in using feed containing eicopentaenoic acid, $\gamma$ linolenic acid, and antioxidants. Several animal studies and one prospective, double blind, randomised controlled trial in 165 patients showed a significant reduction in mortality with such feed (absolute mortality reduction $19.4 \%, \mathrm{P}=0.037) .{ }^{11}$

\section{Fluid management}

The increased pulmonary vascular permeability that characterises acute lung injury suggests that fluid restriction should decrease alveolar lung oedema and improve ventilation. By contrast, reduced circulating volume decreases cardiac output and oxygen delivery and increases renal impairment. Evidence from a well constructed randomised trial in 1000 patients suggests that conservative fluid replacement is associated with significantly improved lung and central nervous system functions and a reduction in the number of days without ventilation and without the need for admission to an intensive care unit, with no increase in non-pulmonary 
organ dysfunction. However, the trial found no significant difference in 60 day mortality. ${ }^{12}$ Similarly, pulmonary artery catheterisation to guide fluid management has shown no mortality advantage over monitoring of central venous pressure. ${ }^{13}$ Fluid intake should therefore be guided by central venous pressure and restricted where possible while maintaining adequate peripheral perfusion.

\section{Glycaemic control}

Strict control of blood glucose (maintaining glucose concentration between $4.4 \mathrm{mmol} / \mathrm{l}$ and $6.1 \mathrm{mmol} / \mathrm{l}$ ) affords a survival advantage to most critically ill patients, although no studies have been conducted exclusively in those with acute respiratory distress syndrome. ${ }^{14}$

\section{Mechanical ventilation Lung protection}

Although some patients with acute lung injury can be managed using non-invasive ventilation, most require endotracheal intubation. The characteristic distribution of lung injury means that regions that are relatively unaffected receive a disproportionate volume of the delivered breath and are therefore at risk of overdistension (volutrauma), especially if the positive pressure is high, which can lead to barotrauma.

Volutrauma and cyclical opening and closing of damaged lung (atelectrauma) are thought to generate proinflammatory mediators (biotrauma). A landmark multicentre, randomised trial was stopped after enrolling 861 patients, because it found that low tidal volume ventilation $(6 \mathrm{ml} / \mathrm{kg}$ of predicted body weight $)$ afforded a significant mortality advantage $(\mathrm{P}=0.007)$ when compared with a standard approach (such as $12 \mathrm{ml} / \mathrm{kg}$ ). ${ }^{15}$ This "lung protective" technique can result in reduced clearance of carbon dioxide $\left(\mathrm{CO}_{2}\right)$, although evidence is lacking to determine the level of consequent acidosis that is safe. In practice, "permissive" hypercapnia is an acceptable side effect as long as oxygenation is not compromised and the $\mathrm{pH}$ is maintained above 7.2 .

\section{A PATIENT'S PERSPECTIVE}

I was 57 years old when my nightmare began on 5 July 2005. I had flu-like symptoms and breathing difficulties.

I was taken to hospital with suspected pneumonia and three hours later was transferred to intensive care and put on a ventilator.

My family was told I had legionnella and acute respiratory distress syndrome and had a $30 \%$ chance of survival. Four weeks later I was transferred to the Royal Brompton Hospital and after five days was given a tracheostomy.

I couldn't speak and was so weak: I couldn't hold a pen, scratch my nose, or move my body.

I went home on 21 September with a walking stick.

What a shock! I was so weak. I was followed up at ICU outpatients at the Brompton and have been told that my lung function is now normal. I do have some numbness in my fingers and the front of my legs, but this doesn't stop me doing the things that I could do before my illness.

I am a caretaker at a college and went back to work in December 2005, and life is wonderful again.

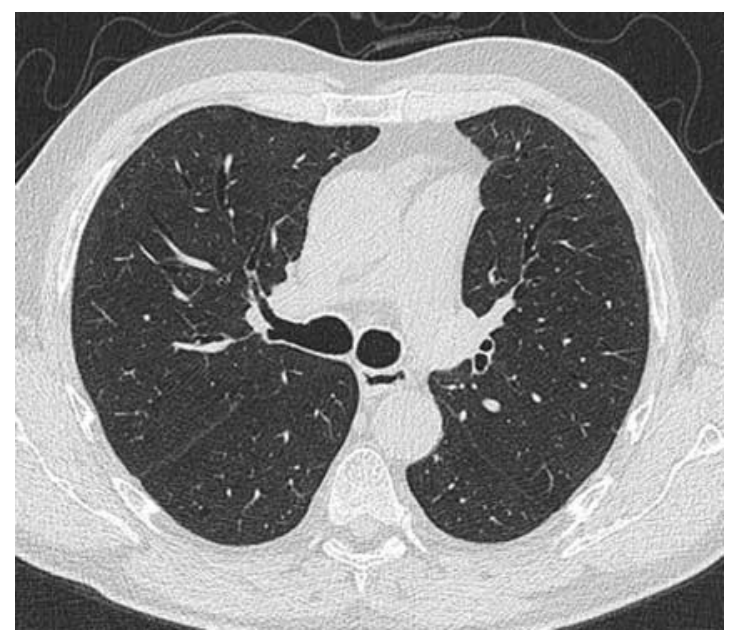

Fig 2 | CT one year later in same patient as in figure 1

\section{Positive end expiratory pressure}

The application of positive end expiratory pressure improves oxygenation by increasing functional residual capacity, recruiting small airways, and improving ventilation and perfusion mismatch by reducing intrapulmonary shunting of blood through collapsed alveoli. Minimising cyclical alveolar collapse and reopening positive end expiratory pressure may result in less ventilator associated lung injury, but high levels can cause circulatory depression and lung injury from overdistension of recruitable lung units.

However, a randomised trial including 549 patients with acute lung injury or acute respiratory distress syndrome showed ventilating patients with lower $8.3 \mathrm{~cm}$ $\left.\mathrm{H}_{2} \mathrm{O}\right)$ or higher $\left(13.2 \mathrm{~cm} \mathrm{H} \mathrm{H}_{2} \mathrm{O}\right)$ levels of positive end expiratory pressure does not influence mortality, ventilator-free days, days spent in intensive care or breathing without assistance, barotrauma, or days without organ failure. ${ }^{16}$ How the use of positive end expiratory pressure and recruitment manoeuvres (and the strategies for setting these) may be used as adjuncts to the protective ventilatory approaches outlined above has been the subject of two large scale, recently completed but unpublished randomised trials (www. abstracts2view.com/ats07/view.php?nu=ATS07L _2793\&terms, www.abstracts2view.com/ats07/ view.php?nu=ATS07L_2979\&terms). Until then it remains reasonable to set a positive end expiratory pressure level just above the lower inflection point on the static pressure-volume curve, to optimise alveolar recruitment while minimising shear stress.

\section{Prone ventilation}

Moving patients with acute respiratory distress syndrome into the prone position has consistently been shown to improve oxygenation initially in about $60 \%$ of cases, but not improve mortality. ${ }^{17}$ However, no large randomised controlled trials have been conducted, and in our opinion this difficult manoeuvre should be reserved for patients in whom adequate oxygenation cannot be achieved by lung protective mechanical ventilation alone (fig 3). 


\section{Box 2 |Acute lung injury: differential diagnoses}

- Cardiogenic pulmonary oedema: excluded by using echocardiography

- Acute interstitial pneumonia: a rare rapidly progressing form of lung injury presenting in previously healthy individuals. Diagnosis is made clinically with pathological confirmation. Bronchoalveolar lavage characteristically shows both eosinophils and neutrophils

- Diffuse alveolar haemorrhage: consider when a patient with acute respiratory failure has an unexplained drop in haemoglobin concentration. If haemoptysis is not present, blood is usually seen at bronchoscopy (post-intubation). Haemosiderin laden macrophages appear after 48 hours and are diagnostic

- Idiopathic acute eosinophilic pneumonia: characterised by cough, dyspnoea, fever, and occasionally chest pain in previously healthy individuals. Raised eosinophils (typically $40 \%$ ) are seen in the bronchoalveolar lavage fluid and usually in the blood. There is a rapid response (normally within 48 hours) to corticosteroids

- Malignancy, particularly lymphangitis carcinomatosis: this can mimic acute respiratory distress syndrome when it disseminates quickly throughout the lung. Bronchoscopy with bronchoalveolar lavage and biopsy help to differentiate between the two

\section{Other ventilatory techniques}

Interest in high frequency ventilation or oscillation - in which small tidal volumes (less than anatomical deadspace) are administered at very high frequencies and gas exchange occurs by convection-has grown since the introduction of protective ventilatory strategies. ${ }^{18}$ Currently, no clear evidence indicates whether high frequency ventilation reduces mortality or long term morbidity in patients with acute lung injury or respiratory distress syndrome.

\section{Non-ventilatory adjuncts to gas exchange Inhaled nitric oxide}

Nitric oxide is an endogenous vasodilator. When administered by inhalation at concentrations up to 20 parts per million, it reduces pulmonary vascular resistance. Although about $60 \%$ of patients with acute lung injury have an initial noticeable improvement in oxygenation, the effect is transient (48 hours) and does not confer mortality benefit or reduction in the duration of mechanical ventilation. ${ }^{19}$ Authorities suggest that nitric oxide should not be used routinely but be reserved for patients in whom adequate oxygenation cannot be achieved by lung protective mechanical ventilation and prone positioning (fig 3$).{ }^{20}$

\section{Nebulised prostacyclin}

Prostacyclin is a second endogenous vasodilator with similar physiological effects to nitric oxide. When

\section{Table 2 | Investigations in patients with acute lung injury or acute respiratory distress syndrome}

Test

Chest radiography

Arterial blood gases

Echocardiography

Computed tomography thorax

(figs 1 and 2)

Fibreoptic bronchoscopy with

bronchoalveolar lavage

\section{How does it help?}

New, bilateral, diffuse, patchy, or homogeneous pulmonary infiltrates consistent with pulmonary oedema define both conditions

Indicates severity of hypoxaemia, defining acute lung injury and acute respiratory distress syndrome

Helps to differentiate acute lung injury from cardiogenic pulmonary oedema

Aids identification of pulmonary causes of acute lung injury

(such as pneumonia, lung abscess) and detection of complications such as pneumothoraces and pleural effusions

Helps to exclude infection, particularly in patients who are not improving despite treatment

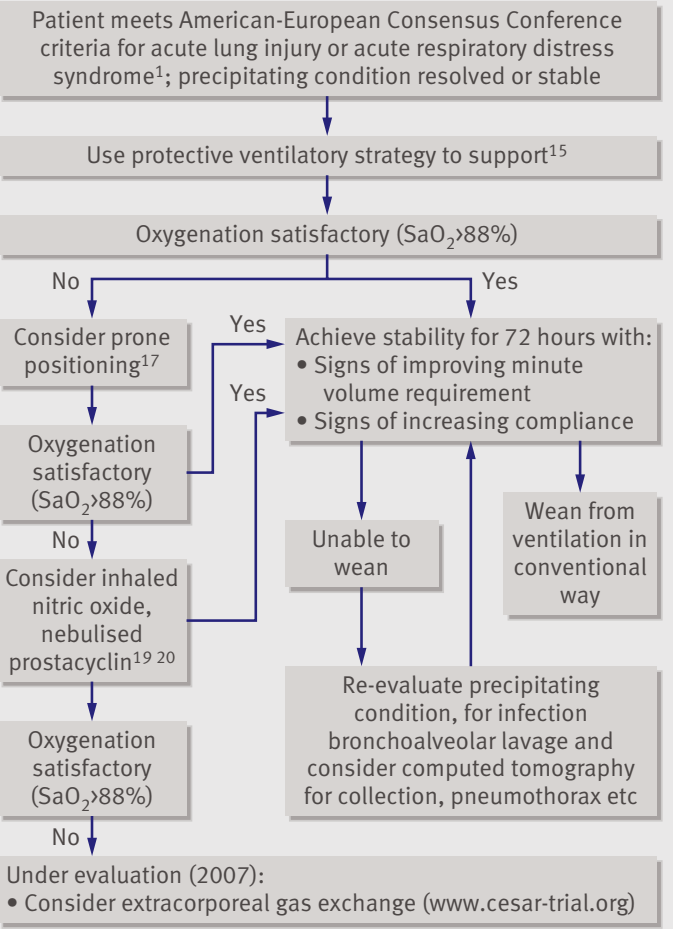

Fig 3 | Our approach to the application of mechanical ventilatory support, non-ventilatory adjuncts to gas exchange, and pharmacotherapy in patients with acute lung injury and acute respiratory distress syndrome

nebulised, it has an equivalent effect on pulmonary vasodilation and oxygenation but is easier to administer, has harmless metabolites, and requires no special monitoring. However, no large randomised controlled trials in acute respiratory distress syndrome have been conducted.

\section{Surfactant}

Although patients with acute respiratory distress syndrome have decreased and dysfunctional surfactant, no benefit has been found after the administration of both natural and synthetic formulations - in terms either of mortality or of the need for mechanical ventilation. By contrast, significant improvements in oxygenation have been found during the initial 24 hours of treatment. ${ }^{21}$ This treatment is not yet available outside clinical trials.

\section{Extracorporeal gas exchange}

The techniques involved in extracorporeal membrane oxygenation are numerous. No survival benefit has been seen among patients with acute respiratory distress syndrome in the sole randomised clinical trial of extracorporeal membrane oxygenation. ${ }^{22}$ However, the results of a study comparing transport to a centre that offers extracorporeal membrane oxygenation versus locally applied conventional ventilation in patients with acute respiratory failure are awaited (www.cesar-trial.org). 


\section{Pharmaceutical interventions Corticosteroids}

A well constructed, multicentre, double blind, randomised controlled trial in 180 patients focusing on the use of corticosteroids in late (fibroproliferative) acute respiratory distress syndrome has shown that methylprednisolone does not influence 60 day mortality. ${ }^{23}$ However, steroid recipients had an increased number of ventilator and shock-free days during the first 28 days (with improved respiratory compliance, oxygenation, and blood pressure) and fewer days of vasopressor therapy. The corticosteroid group had a higher rate of neuromuscular weakness, and those started on methylprednisolone more than 14 days after the onset of acute respiratory distress syndrome may have had an increased risk of death. ${ }^{23}$

The routine use of corticosteroids in patients with persistent acute respiratory distress syndrome is therefore currently not recommended. Although some clinicians have suggested that low doses may be efficacious in patients in septic shock and relative adrenal insufficiency, the preliminary results of a recently completed large scale trial have shown no survival or other advantage (clinicaltrials.gov/ct/show/NCT00147004).

\section{Other pharmacotherapies}

Several potential therapeutic interventions have been used in trials in acute respiratory distress syndrome. Those that have not been shown to confer survival benefit include a variety of antioxidants, $\beta$ - 2 adrenergic receptor agonists, lisofylline, prostaglandin $\mathrm{E}_{1}$, pentoxifylline, interleukin 10, neutrophil elastase inhibitors, granulocyte macrophage colony stimulating factor, dazoxiben, indometacin, and aciclovir. A Cochrane review concluded that there was insufficient evidence to support the application of any specific pharmacotherapy. ${ }^{24}$

\section{When is a patient ready to wean from mechanical ventilation?}

Although studies have not identified the optimal arterial oxygen tension in critical illness, saturations $\left(\mathrm{SaO}_{2}\right)$ in excess of $88 \%$ are a reasonable target in individuals without other relevant disorders (such as cardiovascular insufficiency). A period during which ventilatory stability or improving compliance and minute

\section{UNANSWERED RESEARCH QUESTIONS AND ONGOING RESEARCH}

\section{Trials completed but not yet formally reported}

- UK study comparing transport of patients with severe acute respiratory failure to a centre providing extracorporeal support with conventional ventilation methods applied locally (www.cesar-trial.org)

New registered trials of potential pharmacological interventions in patients with acute lung injury registered at Clinical Trials.gov

- New trial of safety and efficacy of a recombinant chimeric monoclonal antibody against CD14 (IC14) in hospitalised patients with acute lung injury (clinicaltrials.gov/ct/show/NCT00233207)

- Phase II clinical trial of activated protein C (Xigris) versus placebo for the treatment of acute lung injury (clinicaltrials.gov/ct/show/NCT00112164)
Box 3 Problems encountered after survival from acute respiratory distress syndrome $\mathrm{e}^{30}$

- Reduced body weight

- Poor functional physical capacity

- Persistent pain at the site of chest drain insertion

- Entrapment neuropathies

- Heterotrophic ossification causing enlargement and immobility of large joints

- The cosmetic appearance of tracheostomy sites

- Fixed deformities of fingers or frozen shoulders

- Low quality of life score (below that of age and sex matched control) at one year

volume requirement are observed is desirable before weaning is started in the conventional manner (fig 3).

\section{How many patients survive and what is their quality of life?}

The findings of a paper in 1985 found that most patients with acute lung injury who fail to survive seem to die from multiple organ system failure rather than from pulmonary insufficiency. ${ }^{25}$ More recently, clinical experimental evidence suggests that multiple organ system failure occurs partly through dissemination of inflammatory cytokines from the alveolar space into the pulmonary and systemic circulations, a phenomenon reduced by lung protection strategies of mechanical ventilation. ${ }^{26}$

In the Unites States alone, acute lung injury is associated with 74500 deaths annually and the care of such patients consumes 3.6 million hospital days. ${ }^{4}$ Risk factors associated with a poor outcome include advanced age, sepsis, liver disease, and non-pulmonary organ dysfunction. ${ }^{2728}$ In Europe, a prospective multinational study has reported crude mortality rates for intensive care units and hospitals of $22.6 \%$ and $32.7 \%$ respectively for acute lung injury and $49.4 \%$ and $57.9 \%$ respectively for acute respiratory distress syndrome. ${ }^{10}$ In a UK centre a significant reduction in mortality was seen from $66 \%$ to $34 \%$ during $1990-7 .^{29}$

Persistent morbidity after discharge from intensive care is substantial. A well constructed prospective longitudinal study in 109 survivors of acute respiratory distress syndrome showed that three months after discharge from intensive care, patients had a mild to moderate restrictive pattern on lung function testing, with a mild to moderate reduction in carbon monoxide diffusion capacity. A better functional status was associated with the absence of systemic corticosteroid treatment and with illness acquired during a stay in intensive care, as well as with rapid resolution of lung injury and multi organ failure. ${ }^{30}$ See box 3 for an outline of problems encountered after survival from acute respiratory distress syndrome.

Intensive care follow-up clinics are in their infancy. However, problems encountered by patients with acute lung injury and other critical illnesses suggest that these clinics, with multidisciplinary input from 


\section{SUMMARY POINTS}

Acute lung injury and its extreme manifestation, the acute respiratory distress syndrome, complicate a variety of serious medical and surgical conditions, not all of which affect the lung directly

Dyspnoea is the commonest presenting symptom; clinical signs are those of pulmonary oedema

Early admission to intensive care is needed; the precipitating illness should be identified and managed aggressively

Protective techniques of mechanical ventilatory support reduce mortality

Rigorous application of general supportive measures is likely to improve outcome

Non-ventilatory adjuncts to gas exchange generally improve oxygenation but do not reduce mortality

Although death rates are falling, long term debility in survivors is considerable

appropriate healthcare professionals, are likely to be necessary and helpful.

Contributors: Both authors contributed to the collection of data and to the text of the paper. TWE is the guarantor.

Competing interests: None declared

Provenance and peer review: Commissioned and externally peer reviewed.

1 Bernard GR, Artigas A, Brigham KL, Carlet I, Falke K, Hudson L, et al. The American-European consensus conference on ARDS. Definitions, mechanisms, relevant outcomes, and clinical trial coordination. Am J Respir Crit Care Med 1994;149:818-24.

2 Goss CH, Brower RG, Hudson LD, Rubenfeld GD, ARDS Network. Incidence of acute lung injury in the United States. Crit Care Med 2003;31:1607-11.

3 MacCallum NS, Evans TW. Epidemiology of acute lung injury. Curr Opin Crit Care 2005;11:43-9.

4 Rubenfeld GD, Caldwell E, Peabody E, Weaver J, Martin DP, Neff M, et al. Incidence and outcomes of acute lung injury. $N$ Engl J Med 2005:353:1685-93.

5 Gong MN, Thompson BT, Williams P, Pothier L, Boyce PD, Christiani DC. Clinical predictors of and mortality in acute respiratory distress syndrome: potential role of red cell transfusion. Crit Care Med 2005;33:1991-8.

6 Fowler AA, Hamman RF, Zerbe GO, Benson KN, Hyers TM. Adult respiratory distress syndrome. Prognosis after onset. Am Rev Respir Dis 1985;132:472-8.

7 Wind J, Versteegt J, Twisk J, van der Werf TS, Bindels AJ, Spijkstra JJ, et al. Epidemiology of acute lung injury and acute respiratory distress

\section{ADDITIONAL EDUCATIONAL RESOURCES}

Resources for health professionals

- NHLBI Acute Respiratory Distress Syndrome Network (www.ardsnet.org) - Large US based research group (sponsored by the National Institutes of Health) investigating new treatments for acute lung injury and acute respiratory distress syndrome

\section{Resources for patients}

- UK Intensive Care Society (www.ics.ac.uk)—Has information for patients and relatives, including two useful publications: Your Questions Answered and Critical Insight-An Intensive Care Society (ICS) Introduction to UK Adult Critical Care Services

- PatientUK (www.patient.co.uk)—Website providing the same free, current health information and leaflets that are often provided by general practitioners to patients during consultations; has a section devoted to intensive care and critical care

- Royal College of Physicians (www.rcplondon.ac.uk)Website of the Royal College of Physicians of London, which has an active patient and carer forum with representation on the college's Critical Care Committee syndrome in the Netherlands: a survey. Respir Med 2007;6 Jul (Epub ahead of print) doi: 10.1016/j.rmed.2007.05.021

8 Gattinoni L, Caironi P, Cressoni M, Chiumello D, Ranieri VM, Quintel M, et al. Lung recruitment in patients with the acute respiratory distress syndrome. N Engl J Med 2006;354:1775-86.

9 Suntharalingam G, Regan K, Keogh BF, Morgan CJ, Evans TW. Influence of direct and indirect etiology on acute outcome and 6-month functional recovery in acute respiratory distress syndrome. Crit Care Med 2001;29:562-6.

10 Brun-Buisson C, Minelli C, Bertolini G, Brazzi L, Pimentel J, Lewandowski K, et al. Epidemiology and outcome of acute lung injury in European intensive care units. Results from the ALIVE study. Intensive Care Med 2004;30:51-61.

11 Pontes-Arruda A, Aragao AM, Albuquerque JD. Effects of enteral feeding with eicosapentaenoic acid, gamma-linolenic acid, and antioxidants in mechanically ventilated patients with severe sepsis and septic shock. Crit Care Med 2006;34:2325-33.

12 National Heart, Lung, and Blood Institute Acute Respiratory Distress Syndrome (ARDS) Clinical Trials Network. Comparison of two fluid-management strategies in acute lung injury. $N$ Engl I Med 2006;354:2564-75.

13 National Heart, Lung, and Blood Institute Acute Respiratory Distress Syndrome (ARDS) Clinical Trials Network. Pulmonary-artery versus central venous catheter to guide treatment of acute lung injury. N Engl J Med 2006;354:2213-24.

14 Finney SJ, Zekveld C, Elia A, Evans TW. Glucose control and mortality in critically ill patients. JAMA 2003;290:2041-7.

15 Acute Respiratory Distress Syndrome Network. Ventilation with lower tidal volumes as compared with traditional tidal volumes for acute lung injury and the acute respiratory distress syndrome. N Engl J Med 2000;342:1301-8.

16 Brower RG, Lanken PN, MacIntyre N, Matthay MA, Morris A, Ancukiewicz M, et al. Higher versus lower positive end-expiratory pressures in patients with the acute respiratory distress syndrome. N Engl J Med 2004;351:327-36.

17 Mancebo J, Fernandez R, Blanch L, Rialp G, Gordo F, Ferrer M, et al. A multicenter trial of prolonged prone ventilation in severe acute respiratory distress syndrome. Am J Respir Crit Care Med 2006;173:1233-9.

18 Wunsch $\mathrm{H}$, Mapstone J. High-frequency ventilation versus conventional ventilation for treatment of acute lung injury and acute respiratory distress syndrome. Cochrane Database Syst Rev 2004; (1):CD004085.

19 Griffiths MJ, Evans TW. Inhaled nitric oxide therapy in adults. N Engl J Med 2005;353:2683-95.

20 Adhikari NK, Burns KE, Freidrich JO, Granton JT, Cook DJ, Meade MO. Effect of nitric oxide on oxygenation and mortality in acute lung injury: systematic review and meta analysis. BMJ 2007;334:779-82.

21 Spragg RG, Lewis JF, Walmrath HD, Johannigman J, Bellingan G, Laterre PF, et al. Effect of recombinant surfactant protein C-based surfactant on the acute respiratory distress syndrome. $N$ Engl J Med 2004;351:884-92.

22 Morris AH, Wallace CJ, Menlove RL, Clemmer TP, Orme JF Jr, Weaver LK, et al. Randomized clinical trial of pressure-controlled inverse ratio ventilation and extracorporeal $\mathrm{CO} 2$ removal for adult respiratory distress syndrome. Am J Respir Crit Care Med 1994;149:295-305.

23 National Heart, Lung, and Blood Institute Acute Respiratory Distress Syndrome (ARDS) Clinical Trials Network. Efficacy and safety of corticosteroids for persistent acute respiratory distress syndrome. N Engl J Med 2006;354:1671-84.

24 Adhikari NK, Burns KE, Meade MO. Pharmacologic therapies for adults with acute lung injury and acute respiratory distress syndrome. Cochrane Database Syst Rev 2004;(4):CD004477.

25 Montgomery AB, Stager MA, Carrico CJ, Hudson LD. Causes of mortality in patients with the adult respiratory distress syndrome. Am Rev Respir Dis 1985;132:485-9.

26 Ranieri VM, Suter PM, Tortorella C, de Tullio R, Dayer JM, Brienza A, et al. Effect of mechanical ventilation on inflammatory mediators in patients with acute respiratory distress syndrome: a randomized controlled trial. JAMA 1999;282:54-61.

27 Ely EW, Wheeler AP, Thompson BT, Ancukiewicz M, Steinberg KP, Bernard GR. Recovery rate and prognosis in older persons who develop acute lung injury and the acute respiratory distress syndrome. Ann Intern Med 2002;136:25-36.

28 Doyle RL, Szaflarski N, Modin GW, Wiener-Kronish JP, Matthay MA. Identification of patients with acute lung injury. Predictors of mortality. Am J Respir Crit Care Med 1995;152:1818-24.

29 Abel SJ, Finney SJ, Brett SJ, Keogh BF, Morgan CJ, Evans TW. Reduced mortality in association with the acute respiratory distress syndrome (ARDS). Thorax 1998;53:292-4.

30 Herridge MS, Cheung AM, Tansey CM, Matte-Martyn A, Diaz-Granados N, Al-Saidi F, et al. One-year outcomes in survivors of the acute respiratory distress syndrome. $N$ Engl J Med 2003;348:683-93. 